\title{
Perceptions of Mentoring Types by Doctoral Students and Mentors in Economy and Business Administration
}

\author{
Ana Arzenšek \\ Faculty of Management, University of Primorska, Koper, Slovenia \\ Email: ana.arzensek@fm-kp.si
}

Received 18 May 2016; accepted 18 July 2016; published 25 July 2016

\begin{abstract}
A preliminary study has been conducted in order to assess doctoral student-faculty mentorship relations in the fields of Economy and Business administration. The overarching aim was to explore expectations and critical issues in the experiences of mentoring types by doctoral students and mentors. A total of 12 semi-structured interviews were conducted in two Slovenian public universities. The results show to some extent opposing expectations of PhD students and mentors regarding instrumental mentoring and psychosocial mentoring in practices. Implications are discussed and implications for further studies are provided.
\end{abstract}

\section{Keywords}

Relationship, Mentors, PhD Students, Instrumental Mentoring, Psychosocial Mentoring, Sponsorship

\section{Introduction}

In Slovenia, a total of $8.8 \%$ of all doctoral students (SURS 2016) attended doctoral programs in Economics and Business Administration fields in the 2011/2012 academic year. A relatively high percentage of doctoral students according to the needs of Slovenian economy create a specific context in relation mentor-doctoral students as young $\mathrm{PhD}$ holders encounter uncertain future after completing their studies.

The present study aimed at determining the roles and expectations of both mentors and doctoral students as well as determining to which degree perceptions regarding mentoring type of students and mentors are matched [1] [2]. In order to improve the quality of the mentoring practices in the selected fields, information about doctoral students' perceptions and expectations of their relationship with their mentor and vice versa can be useful.

\subsection{PhD Mentoring}

At universities in Slovenia, $\mathrm{PhD}$ candidates write their thesis under the supervision of one or two members of academia. Mentors' primary role is to support and guide the candidate and to evaluate submitted material [2] [3]. The success of the PhD candidate depends on mentors, who not only provide their technical knowledge and de- 
vote time to foster students' progress and attitudes in order to ensure the quality of a thesis, but also develop students' interpersonal and career-building skills.

For Hockey (1991) [4] mentoring is primarily a relationship that heavily influences the mentee's success or failure in obtaining a $\mathrm{PhD}$. Research indicates that the mentor-doctoral student interpersonal relationship is associated with good progress of the work and its completion [5] [6], and with positive psychosocial outcomes, such as student satisfaction, sense of competence [2], identification with the field, confidence about being able to make a contribution [7] and with production of more publications [8]. In spite of this, we know very little about how to reach these kinds of outcomes. It is important to hear the perspectives of both mentors and mentees in order to enhance our understanding of what in the relationship makes them "tick" so as to achieve high performance [9]. Mentors' role in the doctoral students' progression is thus a complex one and needs further investigation.

\subsection{Mentoring Types}

Frequent interaction between students and mentors is positively associated with doctoral completion. These interactions may take place during students' doctoral studies, research development and implementation, writing a thesis or after thesis completion. Working together with mentors of different origins is the opportunity for doctoral students to identify with role models and get support for their academic/professional socialization and development [10]. Mentoring can be provided in a variety of ways. According to Curtin et al. (2014), three critical forms of mentoring in academic settings have been identified:

Instrumental mentoring is providing mentor explicit support in research methodology, information about procedures and content, raising commitment to ethical issues as well as proactive involvement of a mentor to learn technical skills in the field [7]. Psychosocial mentoring is a degree to which students agree that their mentor provides encouragement and support during periods of doubt and failure. When present, it generates selfefficacy in students during challenging circumstances. Sponsorship represents a degree to which mentors work as gatekeepers by proactively working to advocate opportunities within the institution on students' behalf and recommending them to others as well as opening the doors to their own network of professional contacts [6]. As Mainhard et al. (2006) point out not all the students have the same expectations and needs and not all mentors prefer/are able to provide the expected mentoring type. Also, depending on the phase of the project, candidates might need different approaches in order to complete them.

It is important to determine to which degree each of mentoring types matters in the selected fields of study. Research shows [7] that all three types of mentoring directly predict both self-efficacy and academic career interest by doctoral students as well as their academic aspirations. Several studies have focused on $\mathrm{PhD}$ students in particular disciplines, e.g. Dua 2008 for sociology students; Nolan et al. 2008 for chemistry students; Nakanjako et al. 2014 for health sciences students [11]; Webb et al. 2009 for gerontology students, and found some field-specific types of mentoring support. Research results [7] [12] [13] suggest that the mentoring cultures may vary in different fields, with a strong emphasis on instrumental and sponsorship mentoring in the fields of science, technology, engineering and mathematics (STEM), whereas in non-STEM fields there is a strong emphasis on psychosocial mentoring.

\section{Research Methods}

A qualitative study was conducted in order to gain an in-depth understanding of both students' as well as mentors' experiences and key expectations (Creswell 1998). This approach was chosen because it allows exploration on how the participants perceive their experiences, what meaning they construct to their experience and to assess how different dimensions of their experience are related one to another.

\subsection{Participants}

Twelve interviewees took part in the research. Six individual interviews with current doctoral students (4) and ex-doctoral students (2) who successfully completed their doctoral studies in 2015/2016 were conducted. Three of them were employed at the faculty and three in private sector companies. Furthermore, six individual interviews with faculty mentors who are currently involved in mentoring process ( 1 assistant professor, 2 associate professors and 3 full professors) were conducted. Participants were coming from two (out of three) state-owned Slovenian universities and from the Economy and Business administration fields. 


\subsection{Procedure}

Semi-structured, in-depth, individual interviews were conducted in offices of two (out of three) public Slovenian universities as well as in open space locations and they lasted between 35 and 55 minutes. Interviews were audio-taped with the participants' consent and later transcribed verbatim. Additionally, the interviewer took notes during and after interviews. According to Patton (2002) [14], an interview protocol was designed in order to assure higher interview reliability. At the beginning, the interviewer started with a short introduction to the study and with its ethical considerations. Then, participants explained their views on the 8 open-ended questions (e.g. "How would you describe your relationship with your mentor/mentee?"). A list of themes to be addressed in the interview accompanied the interview progress (e.g. kind of mentor support experienced, kind of mentor support expected, obstacles in mentoring process, relationship outcomes etc.).

\subsection{Data Analysis}

A list of codes was formulated on the basis of study aims. ATLAS.ti program for qualitative data processing was used for the first order data analysis, in which participants' quotes were ascribed to one or more codes. Whenever a new theme occurred, a new code was developed and the material was analysed once more. The second order analysis followed in which meaningful relationships among individual codes were searched for.

\section{Results and Discussion}

As we were interested in exploration of expectations and critical issues in the experiences of mentoring types by doctoral students (abbreviated with S1-6) and mentors (abbreviated with M1-6) in the fields of Economy and Business administration, we present results separately by each mentoring type. We explain the prevailing themes that occurred during data analysis and provide cases of PhD students' and mentors' quotes.

\subsection{Instrumental Mentoring}

During interviews, the students talked extensively about their mentors. As the mentor was perceived as their reference person, students expected support from him/her in order to make progress in their work. The prevailing themes such as support, the absence of support and opposition were found, as the example (supportive behaviour of a mentor) shows: "That he knows his boundaries. To pick up the phone and ask others when he doesn't know something. That he doesn't play god only because he is a mentor. And that he doesn't steal the results from you." (S3)

Relatively high discrepancy was found between experience and expectations of doctoral students and mentors regarding behaviour connected to instrumental mentoring type. Participating students reported much more on unsupportive behaviour, whereas mentors mainly reported on constructive and supportive behaviour with their mentees. Although participants did not represent dyads of mentors and their own mentees, it is assumed that positivity bias occurred in the interviews.

"Providing constant feedback is crucial to achieve a goal. Always when she [doctoral student] sends me part of her work, I sit with it and comment on it a lot... at the end everything is red (laughing)." (M1)

In this interview, the mentor was describing his modus operandi with providing constant feedback to his mentee, which is in line with Aspland et al. (1999) [15] and Rose (2003) [16], who also emphasised the importance of mutual feedback about the research progress. We conclude that a lot of effort is needed in order to minimise the gap between students’ and mentors’ expectation about instrumental mentoring behaviour.

\subsection{Psychosocial Mentoring}

The majority of positive quotes referred to psychosocial mentoring type, which is in line with Curtin et al. (2016), who noted a strong emphasis on psychosocial mentoring in non-STEM fields in comparison to STEM fields. Differences in answers were bigger within groups than among groups. The most often occurring themes within this type of mentoring were: provision of emotional support in difficulties, acting as being equal, recognition of improvement, possessing various personal characteristics (e.g. being nice, having “social sense”). Moreover, interviewees hypothesised that the personality of a student and/or of a mentor is a predominant factor of (un)success in thesis completion. This is in accord with Bair and Haworth (2004) [17], who claim that research 
on psychological variables is crucial for determining differences in student persistence and attrition. More research is needed in order to define which personal factors determine the non-/occurrence of psychosocial mentorship. We will explore these factors quantitatively in the future: "After all, I've made it... I'm a survivor. But it was also because of my mentor, without her motivation. I would have never finished my thesis in time, for sure." (S6)

Predominantly, PhD students were describing positive experience of encouragement and support when faced with difficulties, while minority was reporting experience that was contrary to their expectations regarding instrumental as well as psychosocial type of mentoring: "I know how the mentor shouldn't belike. He should provide support when needed. Mine was not like this at all. When I asked him something, he answered me that as a doctoral student I would have to figure it out by myself. He repeated: go and find it in the articles." (S2)

Five out of six mentors thought supporting students on a psychological level is one of their important tasks during the mentoring process, but not all of them were sure how to handle such situations. They had doubts how much autonomy vs. guidance should they provide at a particular point as well as how much support vs. criticism, which is in line with what Goodman (2006) found in her study.

In addition, more interviewees emphasised the importance of communication skills of a mentor. This is in line with concerns of Paré (2011) [18], who argues that no formal/institutional preparation and support is available to majority of mentors. It is thus necessary to work on the "culture of mentoring" as Rose (2003) names institutional support for mentors in a form of surveys, workshops and lectures etc. The same methods could be used in order to foster more instrumental mentoring behaviour. Enhancing communication among students and mentors might improve the quality of doctoral education and it may represent a competitive advantage to the institution.

\subsection{Sponsorship}

Majority of students that we talked with expected career-building support from their mentors. This is aligned with expectations of the author of this article. The most often occurring themes within this particular type of mentoring were: job related support (e.g. helping to retain the position, connecting a student to "the right people”, career counselling) and support with publications. Majority reported about receiving at least some advice. In one case, a student reported having a mentor, who was not very good in terms of providing technical support on her thesis (instrumental mentoring), but provided valuable insights about worldly matters. As a result, she changed her mind regarding pursuing academic career.

More than half of mentors claimed giving advice and opening the doors is part of their tasks, which was taken seriously by a minority of them, whereas others thought they rather concentrate on the technical part of the process either because they have less opportunities or time to assist their mentees in their future careers. Two of them reported about personal characteristics of the students which may impede their efforts with opening the doors: "I've been pushing really hard and offering a lot of support with the research and with the articles... but he didn't make a move. He was lazy like a fox! Later on I was asked to give a recommendation to this guy. How can I recommend someone with work ethics like this?!” (M4)

We conclude that many opportunities for successful relationships between doctoral students and mentors exist, especially concerning instrumental mentoring type. Future research is needed in order to analyse factors that lead to different expectations and less than ideal results regarding this essential type of mentoring. With this, it will be possible to establish institutional policies that will enhance mentor-doctoral student relationships in Economy and Business administration fields.

\section{References}

[1] Bell-Ellison, B.A. and Dedrick, R.F. (2008) What Do Doctoral Students Value in Their Ideal Mentor? Research in Higher Education, 49, 555-567. http://dx.doi.org/10.1007/s11162-008-9085-8

[2] Mainhard, T., van der Rijst, R., van Tartwijk, J. and Wubbels, T. (2009) A Model for the Supervisor-Doctoral Student Relationship. Higher Education, 58, 359-373. http://dx.doi.org/10.1007/s10734-009-9199-8

[3] Anderson, E. and Shannon, A. (1988) Toward a Conceptualization of Mentoring. Journal of Teacher Education, 39, 38-42. http://dx.doi.org/10.1177/002248718803900109

[4] Hockey, J. (1991) The Social Science PhD: A Literature Review. Studies in Higher Education, 16, 319-332. http://dx.doi.org/10.1080/03075079112331382875

[5] Devos, C., Van der Linden, N., Boudrenghien, G., Azzi, A., Frenay, M., Galand, B. and Klein, O. (2015) Doctoral Su- 
pervision in the Light of the Three Types of Support Promoted in Self-Determination Theory. International Journal of Doctoral Studies, 10, 438-464. http://ijds.org/Volume10/IJDSv10p439-464Devos1858.pdf

[6] Devos, C., Boudrenghien, G., Van der Linden, N., Azzi, A., Frenay, M., Galand, B. and Klein, O. (2016) Doctoral Students' Experiences Leading to Completion or Attrition: A Matter of Sense, Progress and Distress. European Journal of Psychology of Education, 1-17. http://dx.doi.org/10.1007/s10212-016-0290-0

[7] Curtin, N., Malley, J. and Stewart, A.J. (2014) Mentoring the Next Generation of Faculty: Supporting Academic Career Aspirations among Doctoral Students. Research in Higher Education, 1-25.

[8] Titus, S.L. and Ballou, J.M. (2014) Ensuring PhD Development of Responsible Conduct of Research Behaviors: Who's Responsible? Science and Engineering Ethics, 20, 221-235. http://dx.doi.org/10.1007/s11948-013-9437-4

[9] Goodman, S.B. (2006) Autonomy and Guidance in Doctoral Advisement Relationships: A Dialectical Study. The Humanistic Psychologist, 34, 201-222. http://dx.doi.org/10.1207/s15473333thp3403_1

[10] Holley, K.A. and Caldwell, M.L. (2012) The Challenges of Designing and Implementing a Doctoral Student Mentoring Program. Innovative High Education, 37, 243-253. http://dx.doi.org/10.1007/s10755-011-9203-y

[11] Nakanjako, D., Katamba, A., Kaye, D.K., Okello, E., Kamya, M.R., Sewankambo, N. and Mayanja-Kizza, H. (2014) Doctoral Training in Uganda: Evaluation of Mentoring Best Practices at Makerere University College of Health Sciences. BMC Medical Education, 14, 9. http://www.biomedcentral.com/1472-6920/14/9 http://dx.doi.org/10.1186/1472-6920-14-9

[12] Paglis, L.L., Stephen, G.G. and Bauer, T.N. (2006) Does Adviser Mentoring Add Value? A Longitudinal Study of Mentoring and Doctoral Student Outcomes. Research in Higher Education, 47, 451-476. http://dx.doi.org/10.1007/s11162-005-9003-2

[13] Tenenbaum, H.R., Crosby, F.J. and Gliner, M.D. (2001) Mentoring Relationships in Graduate School. Journal of Vocational Behavior, 59, 326-341. http://dx.doi.org/10.1006/jvbe.2001.1804

[14] Patton, M.Q. (2002) Qualitative Evaluation and Research Methods. 3rd Edition, Sage Publications, Thousand Oaks.

[15] Aspland, T., Edwards, H., O’Leary, J. and Ryan, Y. (1999) Tracking New Directions in the Evaluation of Postgraduate Supervision. Innovative Higher Education, 24, 127-147. http://dx.doi.org/10.1023/B:IHIE.0000008150.75564.b3

[16] Rose, G.L. (2003) Enhancement of Mentor Selection Using the Ideal Mentor Scale. Research in Higher Education, 44, 473-494. http://www.jstor.org/stable/40197316 http://dx.doi.org/10.1023/A:1024289000849

[17] Bair, C. and Haworth, J.G. (2004) Research on Doctoral Student Attrition and Retention: A Meta Synthesis. In: Smart, J.C., Ed., Higher Education: Handbook of Theory and Research XIX, Agathon, New York, 481-534.

[18] Paré, A. (2011) Speaking of Writing: Supervisory Feedback and the Dissertation. In: McAlpine, L. and Amundsen, C., Eds., Doctoral Education: Research-Based Strategies for Doctoral Students, Supervisors and Administrators.

\section{Submit or recommend next manuscript to SCIRP and we will provide best service for you:}

Accepting pre-submission inquiries through Email, Facebook, Linkedin, Twitter, etc

A wide selection of journals (inclusive of 9 subjects, more than 200 journals)

Providing a 24-hour high-quality service

User-friendly online submission system

Fair and swift peer-review system

Efficient typesetting and proofreading procedure

Display of the result of downloads and visits, as well as the number of cited articles

Maximum dissemination of your research work

Submit your manuscript at: http://papersubmission.scirp.org/ 